\title{
Work addiction: An organizational behavior as well as an addictive behavior?
}

\author{
Commentary on: Ten myths about work addiction (Griffiths et al., 2018) \\ OREN LIOR, REIZER ABIRA and WEINSTEIN AVIV* \\ Department of Behavioral Science and Integrative Brain and Cognition Center, University of Ariel, Ariel, Israel
}

(Received: July 1, 2018; revised manuscript received: November 5, 2018; accepted: November 6, 2018)

\begin{abstract}
In their critical review, Griffiths et al. (2018) discussed 10 myths in the study of work addiction, and addressed the need to conceptualize and investigate this area of research more carefully. In this commentary, we expand their arguments, suggesting that indeed some of the popular myths have solid evidence-based results in the organizational literature. Yet, some of the arguments are only indirectly related to previous organizational findings. Therefore, we emphasize the need to resolve the ambiguities of work addiction, as well as to develop a comprehensive and interdisciplinary understanding of the well-known phenomenon of addictive work behavior.
\end{abstract}

Keywords: work addiction, organizational behavior, behavioral addiction

Griffiths, Demetrovics, and Atroszko (2018) in their comprehensive review article discuss 10 myths in the study of work addiction. Before relating to these 10 myths, the authors indicated the problematic state of theorizing and research in the field of work addiction, and we would like to relate to the lack of consensus in this field. There are various definitions of work addiction (or workaholism). The number of definitions is almost equal to the number of leading researchers who have studied work addiction. Although some studies defined a workaholic as a person who is highly work-involved, feels driven to work because of inner pressures, and is low in work enjoyment (Spence \& Robbins, 1992, p. 162), other studies emphasized the positive aspects, and defined workaholics as "those who enjoy the act of working, who are obsessed with working, and who devote long hours and personal time to work" (Ng, Sorensen, \& Feldman, 2007, p. 114). Indeed, there is disagreement whether a person who enjoys working hard can be considered addicted to work.

Our commentary addresses the 10 myths mentioned by Griffiths et al. (2018), which provided solid empirical support for the development of the field. We expand some of the ideas that were presented in their work, and add some new empirical and theoretical considerations.

The first myth is that work addiction is a new behavioral addiction. Certainly, work addiction is not a new addiction. However, for many years, systematic research on work addiction was almost non-existent, and writing was almost solely based on anecdotal cases (and also myths, perhaps). According to Clark, Michel, Zhdanova, Pui, and Baltes (2016), 88\% of the entries on workaholism in PsycINFO have been published since 2000 (Bujalski, Hellman, Moskalewicz, Beccaria, \& Rolando, 2018).

It is also noteworthy that work addiction is a somewhat changing phenomenon. Change happens for three reasons: culture, technology, and science. Work addiction can relate to culture that puts much significance on work and career, and even treats individuals according to their professional or material success. National culture is an important determinant of how people construe themselves at work (Gahan \& Abeysekera, 2009), and often views hard work and occupational stress as a badge of honor. A good example of national culture and work behavior is the Japanese phenomenon of "karoshi" mentioned by Griffiths et al. (2018). Modern technology is moving fast, and people today can work from home using technologies such as "Skype." Teleworking is becoming more popular, and the borders between work and family are becoming blurred. Griffiths et al. (2018) mentioned the hypothetical case of research addiction that could fit some scientists who spend most of their waking hours at home in front of their laptops thanks to teleworking. Thankfully, science is also moving, and today we are studying several closely related work behaviors, such as work engagement, flow, work commitment, overcommitment, and work addiction, which are related to individual types of employee wellbeing (Hakanen, Peeters, \& Schaufeli, 2018). For this reason, there is a constant need to develop better models, measures, and definitions that differentiate between these closely related occupational phenomena. Collaboration between occupational psychologists and addiction specialists is extremely important to advancing the study of work addiction.

* Corresponding author: Weinstein Aviv; Department of Behavioral Science and Integrative Brain and Cognition Center, University of Ariel, Science Park, Ariel 40700, Israel; Phone: +972 3907 6555; Fax: +972 3906 6629; E-mails: avivwe@ariel.ac.il; avivweinstein@yahoo.com

This is an open-access article distributed under the terms of the Creative Commons Attribution-NonCommercial 4.0 International License, which permits unrestricted use, distribution, and reproduction in any medium for non-commercial purposes, provided the original author and source are credited, a link to the CC License is provided, and changes - if any - are indicated. 
The second myth is that work addiction is similar to other behavioral addictions. We believe that professional treatment of addictions should come from the understanding that no two addictions are similar. Work addiction, in many senses, is different from other addictions.

According to Sigmund Freud (1926), the aim of life is to love and work; civilization rests on the power of love and the compulsion to work. Indeed, the border between a healthy compulsion to work and work addiction is very delicate, because for most individuals, work is a positive and important experience. For example, according to Spence and Robbins (1992), work enthusiasts are individuals who are high in involvement, drive, and enjoyment from work. Certainly, we cannot imagine drug or alcohol enthusiasts. Interestingly, Snir and Harpaz (2012) introduced the concept of heavy work investment (HWI), claiming that individuals can heavily invest in work for different reasons, and that work addiction is a subtype of HWI, which does not stem from external predictors or from a passion for work. The question when investment in work ceases to be a passion and changes from (positive) engagement to work addiction is not an easy one.

The third myth is that there are only psychosocial consequences of work addiction. We agree with Griffiths et al. (2018) that there are many other consequences of work addiction, including life-threatening physical illnesses. Findings from Clark et al.'s (2016) meta-analysis suggest that in addition to psychosocial consequences (e.g., poor mental health, decreased job and life satisfaction, burnout, and job stress), work addiction is also strongly negatively related to poor physical health including cardiovascular risk $(\rho=-.33)$. Moreover, in a longitudinal study (measurement interval $=7$ months), workaholism was related to increase in ill health (Shimazu, Schaufeli, Kubota, \& Kawakami, 2012). Interestingly, in organizations, workaholism was positively associated with health-related absences (Falco et al., 2013).

The fourth myth is that work addiction and workaholism are the same thing. The term workaholism was coined in fun by an American professor of religion who was attempting to describe his own relationship with work (Oates, 1968). Over the years, the two terms became synonyms and, in our opinion, for the sake of research advancement, the terms work addiction and workaholism should remain synonymous. Clark et al. (2016) concluded that the majority of scholars refer to workaholism as an addiction that involves "compulsion, preoccupied behavior, loss of self-control and continued engagement in the behavior despite negative consequences" (p. 1838). Work addiction has been previously defined as a condition, often referred to as "workaholism," in which the person (called a "workaholic") feels driven or compelled to work, often because feeling guilty while not working (Lumpkin \& Anshel, 2012). Therefore, we cannot agree with Griffiths et al.'s (2018) conclusion that work addiction is a psychological concept rooted in the addiction literature, whereas workaholism is a more general and generic term, which can include both positive and negative aspects. We suggest that although workaholism has been studied in normal working settings and among normal populations, it includes a pathogenic component as well as compulsive behaviors similar to work addiction (Spurk, Hirschi, \& Kauffeld, 2016).
Research in the field of workaholism has been dominated by the addiction model and by the trait theory approach (Sussman, 2012). The addiction model views the phenomenon as an irresistible inner drive to work excessively hard (Andreassen \& Pallesen, 2016). However, no evidence was found that excessive working shares psychophysiological characteristics of established definitions of addiction (McMillan, O'Driscoll, Marsh, \& Brady, 2001), and the phenomenon has been excluded from fifth edition of the Diagnostic and Statistical Manual of Mental Disorders (DSM-5; American Psychiatric Association, 2013). In contrast, the trait theory approach explains excessive working as a manifestation of a "stable individual difference characteristic" (Burke, 2004, p. 421), comprising the psychological dimensions of high work involvement, high drive, and low work enjoyment (Spence \& Robbins, 1992). Part of the disagreement regarding the theoretical model of workaholism is because workaholism is a multidimensional construct, and researchers tend to disagree on its main dimensions.

The fifth myth is that work addiction occurs exclusively as a consequence of individual factors. We agree that work addiction results from an interaction between many factors including an individual's psychological constitution and the nature of the environment in which the individual lives and works. According to $\mathrm{Ng}$ et al. (2007), a combination of individual dispositions together with specific beliefs and values, resulting from the interaction between one's predisposition and the sociocultural and organizational environment, contributes to the development of work addiction. Personality traits (e.g., compulsivity, obsessiveness, perfectionism, and low self-worth) and values acquired in the socialization process (e.g., achievement and self-direction) can serve as predispositions, whereas professional rules, job demands, career-related variables, and work culture may predispose the individual to work addiction (Andreassen, Nielsen, Pallesen, \& Gjerstad, 2017; Mazzetti, Schaufeli, \& Guglielmi, 2014; Spurk et al., 2016).

The sixth myth is that work addiction only occurs in adulthood. While it is reasonable to assume that work addiction occurs only among working populations, several studies also pointed to study addiction that was found among students, and claimed that this addiction preceded work addiction (Atroszko, Andreassen, Griffiths, \& Pallesen, 2016). In addition, Oren and Ben Noon (2016) found positive correlations between depression, psychological strain, intrusion, and avoidance responses and past compulsive workaholism as reported by partners of new retirees from work (mean age: 66 years). In short, we think that it is too early to conclude that work addiction and its consequences occur only in adulthood.

The seventh myth is that some types of work addiction are positive. We align with most of the studies and agree that work addiction is negative. However, we cannot ignore studies with different findings. For example, Snir and Zohar (2008) found no differences between workaholics and non-workaholics in their levels of physical discomfort and negative affect during the weekend. We posit that such findings can help us better understand work addiction and its consequences. As noted, there are several reasons for excessive work investments, such as engagement (Schaufeli \& Salanova, 2011) or external demands (Snir \& Harpaz, 2012). 
Individuals may also report high levels of involvement, drive, and work enjoyment and therefore be regarded as enthusiastic workaholics (Spence \& Robbins, 1992). The question arises which of these are types of work addiction. We feel that more research and theorizing is necessary before being able to determine the answer to this question, and therefore conclude that all types of work addiction are negative.

The eighth myth is that work addiction is a transient behavioral pattern related to situational factors. On one hand, work addiction was found to be related to stable individual characteristics, such as personality (e.g., type A behavior; $\mathrm{Ng}$ et al., 2007) and demographics (e.g., family dynamics; Robinson, 2013) and therefore should be a persistent pattern of behavior. On the other hand, studies found this behavior to be fostered by situational factors, such as organizational climate (Spurk et al., 2016) and role conflict (Andreassen et al., 2017). The answer to the question whether work addiction is a persistent or transient behavioral pattern can best be provided by longitudinal studies that follow individuals for a long time span. Unfortunately, most of the studies on work addiction are cross-sectional, and longitudinal studies are rare (Clark et al., 2016). In our opinion, longitudinal studies are needed before being able to determine this question.

The ninth myth is that work addiction is a function of the time spent engaging in work. As noted, the controversy about defining work addiction is obvious. We agree with Griffiths et al. (2018) that content and context of the behavior is important in determining work addiction. However, as Clark et al. (2016, p. 1839) mentioned, "Almost every conceptualization of workaholism involves the idea that workaholics work longer and harder than others." In addition, some researchers (Harpaz \& Snir, 2003; Mosier, 1983) used hours worked per week as an indicator of workaholism. Therefore, we cannot minimize the importance of time spent at work as one indicator of work addiction.

The tenth myth is that work addiction is an example of overpathogizing everyday behavior, and that it will never be classified as a mental disorder in the DSM. While only fortunetellers can predict which behavior pattern will never be classified as a mental disorder in the DSM, we agree with Griffiths et al. (2018) that if there are agreed criteria for work addiction and an individual meets those criteria, he or she should be classified as a work addict.

In summary, we believe that Griffiths et al. (2018) have carried out excellent work in clarifying what we already know versus the knowledge that is still missing. We hope that future research advances our knowledge, and enables practitioners to provide help for people suffering from workaholism/work addiction.

Funding sources: No financial support was received for this study.

Authors' contribution: All individuals included as authors of the paper have contributed substantially to the scientific process leading up to the writing of the paper. The authors have contributed to the conception and design of the project, analysis and interpretation of the research, and preparation of the manuscript for publication.

Conflict of interest: The authors have no interests or activities that might be seen as influencing the research (e.g., financial interests in a test or procedure, funding by pharmaceutical companies for research).

\section{REFERENCES}

American Psychiatric Association. (2013). Diagnostic and statistical manual of mental disorders (DSM-5). Washington, DC: American Psychiatric Association.

Andreassen, C. S., Nielsen, M. B., Pallesen, S., \& Gjerstad, J. (2017). The relationship between psychosocial work variables and workaholism: Findings from a nationally representative survey. International Journal of Stress Management. Advance online publication. doi:10.1037/str0000073

Andreassen, C. S., \& Pallesen, S. (2016). Workaholism: An addiction to work. In V. R. Preedy (Ed.), Neuropathology of drug addictions and substance misuse (Vol. 3, pp. 972-983). London, UK: Academic Press.

Atroszko, P. A., Andreassen, C. S., Griffiths, M. D., \& Pallesen, S. (2016). The relationship between study addiction and work addiction: A cross-cultural longitudinal study. Journal of Behavioral Addictions, 5(4), 708-714. doi:10.1556/2006.5. 2016.076

Bujalski, M., Hellman, M., Moskalewicz, J., Beccaria, F., \& Rolando, S. (2018). Depoliticising addiction. Who gets to speak in European press reporting, 1991-2011? Nordic Studies on Alcohol and Drugs, 35(1), 52-68. doi:10.1177/1455072 517753558

Burke, R. J. (2004). Introduction: Workaholism in organisations. Journal of Organisational Change Management, 17(5), 459-470. doi:10.1108/09534810410554489

Clark, M. A., Michel, J. S., Zhdanova, L., Pui, S. Y., \& Baltes, B. B. (2016). All work and no play? A meta-analytic examination of the correlates and outcomes of workaholism. Journal of Management, 42(7), 1836-1873. doi:10.1177/01492063 14522301

Falco, A., Girardi, D., Kravina, L., Trifiletti, E., Bartolucci, G. B., Capozza, D., \& Nicola, A. (2013). The mediating role of psychophysic strain in the relationship between workaholism, job performance, and sickness absence: A longitudinal study. Journal of Occupational and Environmental Medicine, 55(11), 1255-1261. doi:10.1097/JOM.0000000000000007

Freud, S. (1926). Inhibitions, symptoms and anxiety. In J. Strachey \& A. Freud (Eds.), The standard edition of the complete psychological works of Sigmund Freud (pp. 77-175). London: The Hogarth Press.

Gahan, P., \& Abeysekera, L. (2009). What shapes an individual's work values? An integrated model of the relationship between work values, national culture and self-construal. The International Journal of Human Resource Management, 20(1), 126-147. doi:10.1080/09585190802528524

Griffiths, M. D., Demetrovics, Z., \& Atroszko, P. A. (2018). Ten myths about work addiction. Journal of Behavioral Addictions. Advance online publication. doi:10.1556/2006.7.2018.05 
Hakanen, J. J., Peeters, M. C. W., \& Schaufeli, W. B. (2018). Different types of employee well-being across time and their relationships with job crafting. Journal of Occupational Health Psychology, 23(2), 289-301. doi:10.1037/ocp0000081

Harpaz, I., \& Snir, R. (2003). Workaholism: Its definition and nature. Human Relations, 56(3), 291-319. doi:10.1177/00 18726703056003613

Lumpkin, K., \& Anshel, M. H. (2012). Work addiction among intercollegiate sports coaches. Journal of Sport Behavior, 35, 406-432.

Mazzetti, G., Schaufeli, W. B., \& Guglielmi, D. (2014). Are workaholics born or made? Relations of workaholism with person characteristics and overwork climate. International Journal of Stress Management, 21(3), 227-254. doi:10.1037/a0035700

McMillan, L. H., O'Driscoll, M. P., Marsh, V., \& Brady, E. C. (2001). Understanding workaholism: Data synthesis, theoretical critique, and future design strategies. International Journal of Stress Management, 8(2), 69-91. doi:10.1023/ A:1009573129142

Mosier, S. K. (1983). Workaholics: An analysis of their stress success and priorities (Unpublished master's thesis). University of Texas at Austin, Texas.

Ng, T. W. H., Sorensen, K. L., \& Feldman, D. C. (2007). Dimensions, antecedents, and consequences of workaholism: A conceptual integration and extension. Journal of Organizational Behavior, 28(1), 111-136. doi:10.1002/job.424

Oates, W. E. (1968). On being a "workaholic". Pastoral Psychology, 19(8), 16-20. doi:10.1007/BF01785472

Oren, L., \& Ben Noon, Y. (2016). Workaholism, psychological strain and depression among new retirees: Does marital satisfaction and self-esteem moderate the associations? Proceedings of 37 th Stress and Anxiety Research Society Conference, Zagreb, Croatia.
Robinson, B. E. (2013). Chained to the desk: A guidebook for workaholics, their partners and children, and the clinicians who treat them (3rd ed.). New York, NY: New York University Press.

Schaufeli, W., \& Salanova, M. (2011). Work engagement: On how to better catch a slippery concept. European Journal of Work and Organizational Psychology, 20(1), 39-46. doi:10.1080/ 1359432X.2010.515981

Shimazu, A., Schaufeli, W. B., Kubota, K., \& Kawakami, N. (2012). Do workaholism and work engagement predict employee well-being and performance in opposite directions? Industrial Health, 50(4), 316-321. doi:10.2486/indhealth. MS1355

Snir, R., \& Harpaz, I. (2012). Beyond workaholism: Towards a general model of heavy work investment. Human Resource Management Review, 22(3), 232-243. doi:10.1016/j.hrmr. 2011.11.011

Snir, R., \& Zohar, D. (2008). Workaholism as discretionary time investment at work: An experience-sampling study. Applied Psychology, 57(1), 109-127. doi:10.1111/j.1464-0597.2006. 00270.x

Spence, J. T., \& Robbins, A. S. (1992). Workaholics: Definition, measurement, and preliminary results. Journal of Personality Assessment, 58(1), 160-178. doi:10.1207/s1532 7752jpa5801_15

Spurk, D., Hirschi, A., \& Kauffeld, S. (2016). A new perspective on the etiology of workaholism: The role of personal and contextual career-related antecedents. Journal of Career Assessment, 24(4), 747-764. doi:10.1177/106907 2715616127

Sussman, S. (2012). Workaholism: A review. Journal of Addiction Research \& Therapy, 6, 4120. doi:10.4172/21556105.S6-001 